\title{
Mechanical And Microstructural Characterization Of Copper And Carbon Nanotubes Using Nanocomposites
}

\author{
Shridhar Deshpande ${ }^{\# 1}$, Dr.Shrishail Kakkeri ${ }^{* 2}$, Atmanand Anikivi ${ }^{\# 3}$,Chandrahas $\mathrm{M}^{* 4}$ \\ ${ }^{\# 1}$ Assistant Professor, Dept. of ME, \\ Sri Venkateshwara College of Engineering, Bangalore, Karnataka, India \\ ${ }^{* 2}$ Professor and Head, Dept. of ME, \\ Sri Venkateshwara College of Engineering, Bangalore, Karnataka, India \\ ${ }^{\# 3}$ Assistant Professor, Dept. of ME, \\ Sri Venkateshwara College of Engineering, Bangalore, Karnataka, India \\ ${ }^{* 4} \mathrm{PG}$ Scholar, Dept. of ME, \\ Sri Venkateshwara College of Engineering, Bangalore, Karnataka, India \\ ${ }^{\# 1}$ shridhardes@gmail.com, ${ }^{* 2}$ skakssam@gmail.com, ${ }^{\# 3}$ atmanand2015@gmail.com
}

\begin{abstract}
In recent years, carbon nanotubes (CNTs) reinforced Copper matrix composites have gained increased importance. The quality of dispersion, however, is a critical factor which decides the homogeneity and mechanical properties of these composites. Various amounts of well distributed multiwalled carbon nanotubes (MWCNTs) were used as reinforce a $\mathrm{Cu}$ via a powder metallurgy technique. The microstructures of the nanocomposite were observed by conducting scanning electron microscope(SEM) and Pin-on-disk wear tests were performed under different loading conditions, to evaluate the Adhesive wear properties of the different weight ratios of $\mathrm{Cu}-\mathrm{MWCNT}$ nanocomposites. In assessment with the pure $\mathrm{Cu}$, the addition of MWCNTs reduced the coefficient of friction in $\mathrm{Cu}-$ MWCNT nanocomposites. The obtained results explain that additions of MWCNTs can improve the Cu and modify it into a wear resistance material. The MWCNTs plays double roles in improving the wear performance of the nanocomposites, indirectly by influencing the microstructure and mechanical properties of nanocomposites and directly by acting as a lubricating medium.
\end{abstract}

Keyword - Carbon nanotubes, copper powder, Sintering, Microstructure, wear properties.

\section{INTRODUCTION}

For this present research work CNTs were directly procured from united nanotech innovation private limited in hoskote Bengaluru. The United Nanotech Innovations Pvt. LTD as produced the CNTs by Chemical Vapor Deposition Technique. There are two reasons for following up this Method one is the CNTs are produces at lower temperature and second is it lower cost compared to other process.

For this work, pure copper powder is taken as matrix material and MWCNTs as re-inforcement with different weight ratio of re-inforcement composites are prepared by using powder metallurgy technique. The mixing of $\mathrm{Cu} / \mathrm{CNT}$ is done by using ball milling process and the microstructure of $\mathrm{Cu} / \mathrm{CNT}$ is prepared is checked by scanning electron microscope (SEM) and XRD analysis. And the microstructure from SEM indicates proper distribution CNTs in copper matrix of sintered composites. Vickers micro-hardness test is conducted for different percentage of CNT's and Cu composites to know the hardness values The tribology properties such as wear resistance and friction behavior of each specimen is determined by conducting pin-on-disk wear tests and compared with pure copper specimen.

\section{MATERIAL SELECTION}

Following are the nanocomposite material combinations along with their properties are considered for the present work.

Copper: Copper is the third most widely available metal element comprises $8 \%$ of the earth's crust. Pure copper has a characteristic like soft in nature, highly ductile, corrosion resilient and has a high electrical conductivity. It is widely used for foil and conductor cables, but alloying with other elements is necessary to provide the higher strengths needed for other applications.

Multi-walled Nanotubes: MWNTs have excellent properties and are being employed in a large number of commercial applications. MWNTs include several tubes in concentric cylinders as shown in fig. The number of these concentric walls may vary from 6 to 25 or more. The diameter of MWNTs may be $30 \mathrm{~nm}$ when compared to $0.7-2.0 \mathrm{~nm}$ for typical SWNTs. 


\section{B. METHODOLOGY}

Fabrication of Nanocomposites: As per ASTM standards the nanocomposites were made from copper powder and MWCNTs used as filler materials. preparation of nanocomposites is carried out at room temperature by powder metallurgy techniques and a nanocomposite was sintered at $850^{\circ} \mathrm{C}$ temperature for 4 hour and cooled to room temperature.

\section{C.PREPARATION OF SPECIMEN}

Powder Metallurgy Technique(PM): This process consists of three basic steps: powder blending, Die compaction, and sintering. Blending of powders was done in ball milling process, compaction is generally performed at room temperature using hydraulic press machine, and later sintering is usually conducted at atmospheric pressure and under carefully controlled atmosphere.
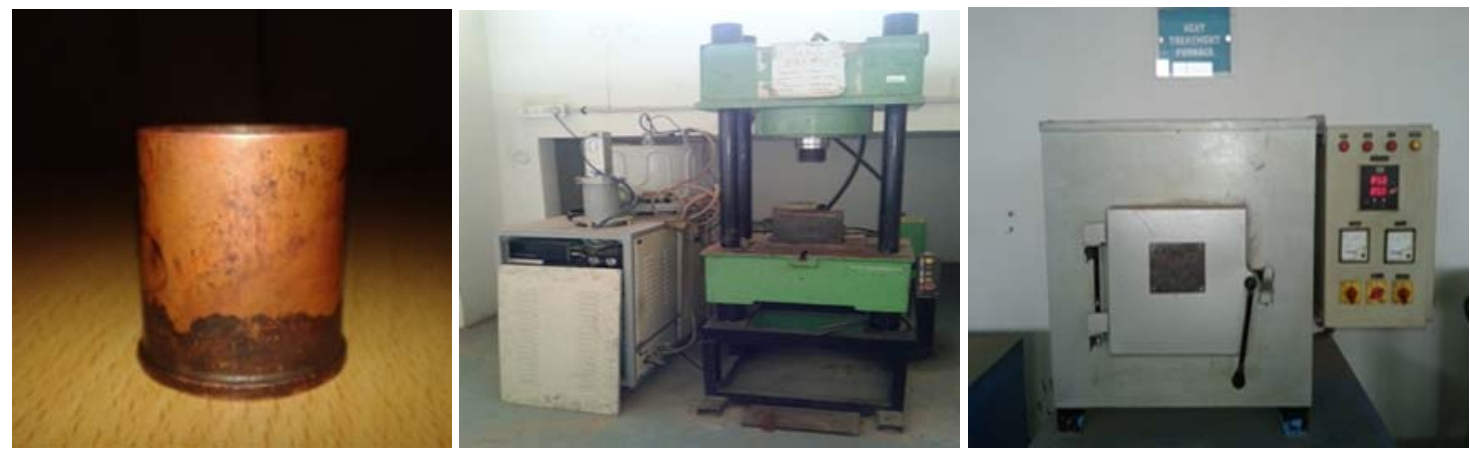

Figure1 (a) copper sleeves used for powder compacting, (b) Hydraulic pressing machine, (c) heating furnace

Preparation of Testing Specimen: Completing the sintering process the sleeves are cooled in room temperature then the outer diameter of sleeves is slowly machined to get the sintered specimen and EDM was done to sintered specimen to obtain testing specimens there after further tests are conducted.

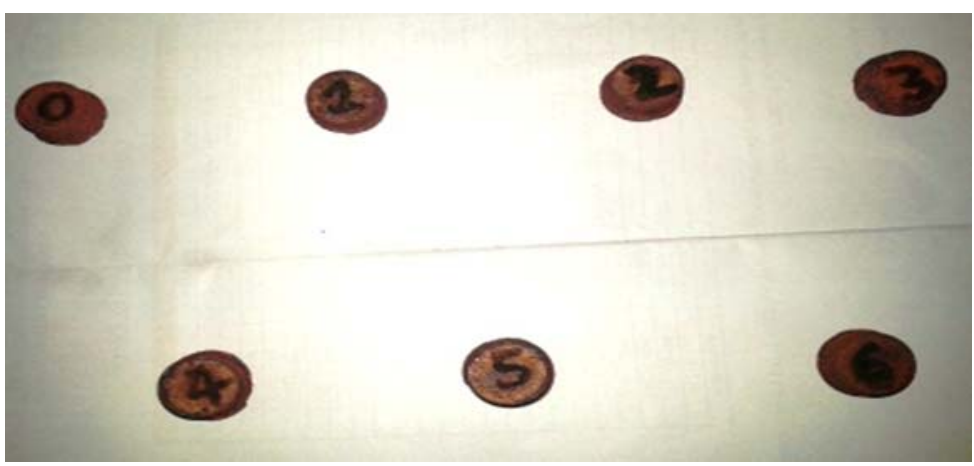

Figure2 Different compositions of $\mathrm{Cu}+\mathrm{CNT}$ 's\% obtained after sintering process

\section{RESULTS AND DISCUSSION}

Microstructure: All technological characteristics of materials are directly connected to their microstructure. In these properties such as strength and deformation, wear and high temperature behavior, and corrosion. Some of these characteristics can be modified by making slight changes in the microstructure. scanning electron microscope (SEM) as shown below.

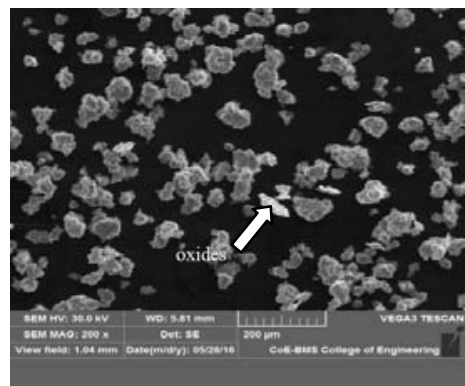

Fig 3(a)

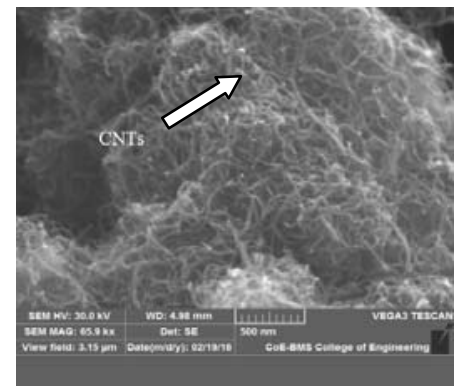

Fig 3(b)

Figure 3(a), (b) SEM image of Copper powder and Carbon nanotubes 


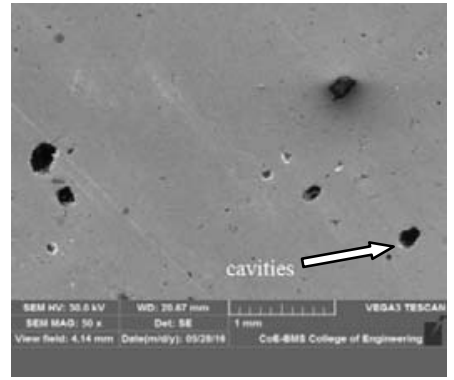

Fig 4(a)

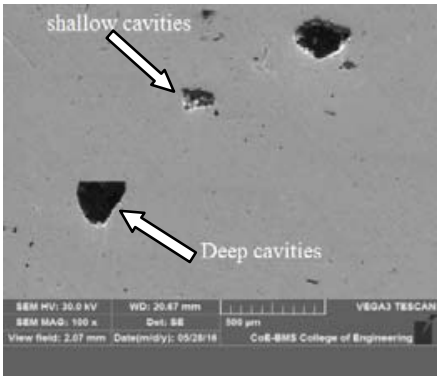

fig 4(b)

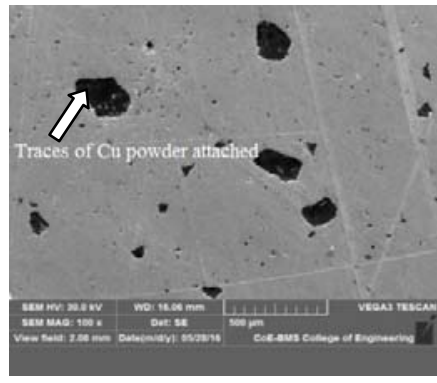

fig(c)

Figure 4(a), (b), and (c) SEM images of $\mathrm{Cu}+\mathrm{CNTs}$ with different weight ratios

Vickers Hardness test: This test conducted to evaluate the Vickers hardness of given specimen that can be used on very hard materials. The hardness of Cu+ MWCNT's nanocomposites and pure copper was measured using Vickers hardness test machine. Hardness test was conducted in CML commercial laboratory readings are shown in table

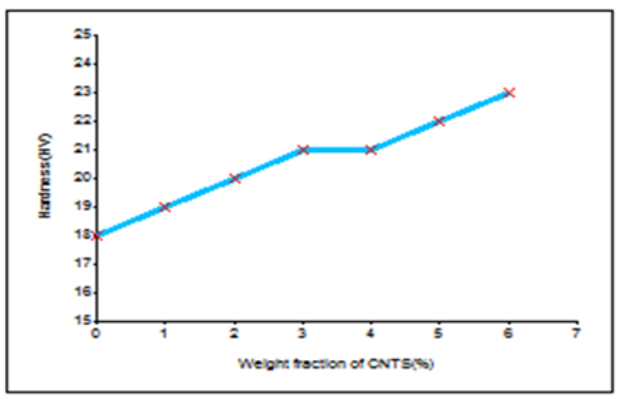

Fig 5

Fig 5 Effect of CNTs weight fractions on the hardness of $\mathrm{Cu}+\mathrm{MWCNTs}$ nanocomposite

Wear Testing: The wear test was conducted for five specimens including pure copper specimen and following are the tabulated wear test results as per ASTM standard G99 obtained under varying load and speed conditions.

Specification of Tribometer used for wear testing

1. Disc rotation speed -100 to $2000 \mathrm{rpm}$

2. Track diameter -50 to $100 \mathrm{~mm}$

3. Wear range -1 to $2000 \mu$

4. Load -5 to $200 \mathrm{~N}$

5. Power- 2 KVA, 230 V

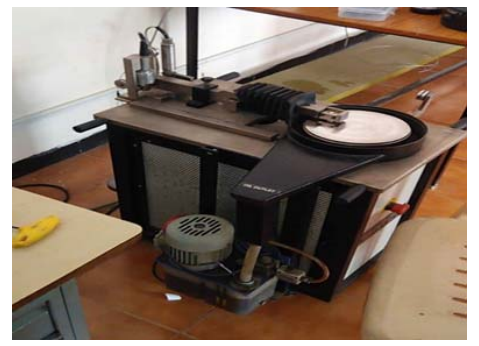

Fig6 (a) Pin-on-Disc Apparatus used for wear test

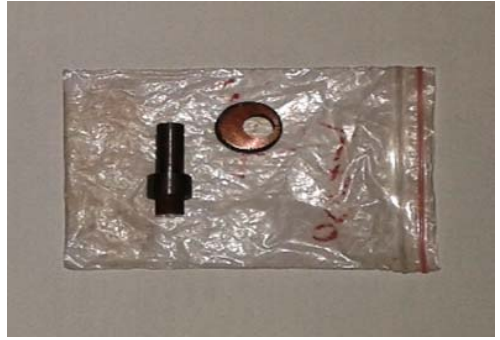

Fig6 (b) Specimen used for wear testing

The variation coefficient of friction for different weight fraction is shown in graphs below. Wear and friction coefficient graph for different weight percent of $\mathrm{Cu}+\mathrm{MWCNTs} \%$. 


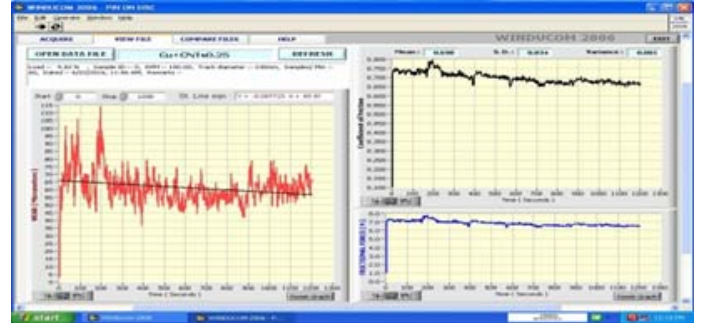

Fig 7(1)

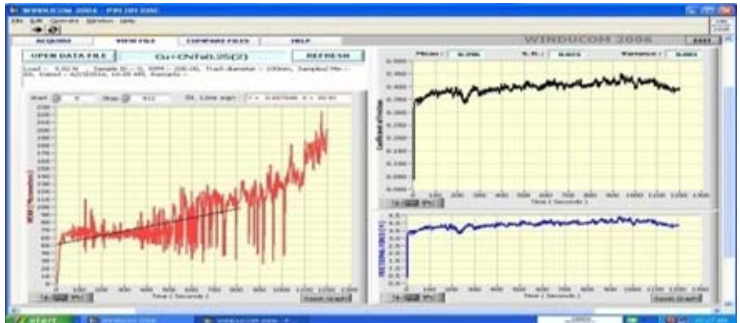

Fig 7(2)

Fig 7(1) $\mathrm{Cu}+\mathrm{MWCNTs} 0.25 \%$ for load $1 \mathrm{~kg}$ and with speed $100 \mathrm{rpm}$. Fig 7(2) $\mathrm{Cu}+\mathrm{MWCNTs} 0.25 \%$ for load $1 \mathrm{~kg}$ and with speed 200rpm

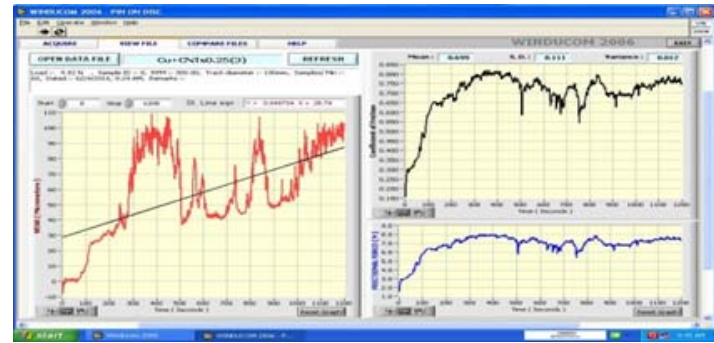

Fig 7(3)

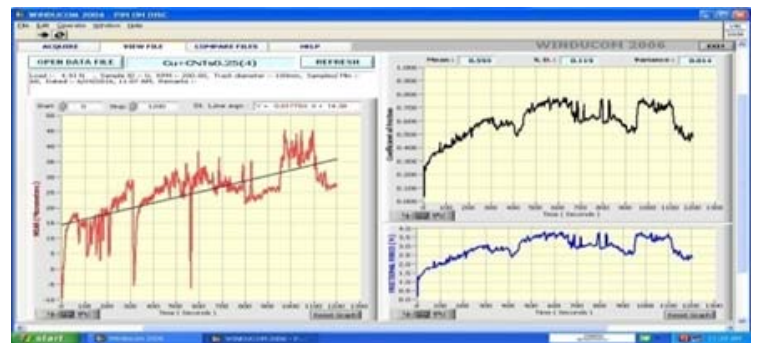

Fig 7(4)

Fig 7(3) $\mathrm{Cu}+\mathrm{MWCNTs} 0.25 \%$ for load $1 \mathrm{~kg}$ and with speed 300 rpm Fig 7(4) Cu+MWCNTs $0.25 \%$ for load $0.5 \mathrm{~kg}$ and with speed 200rpm

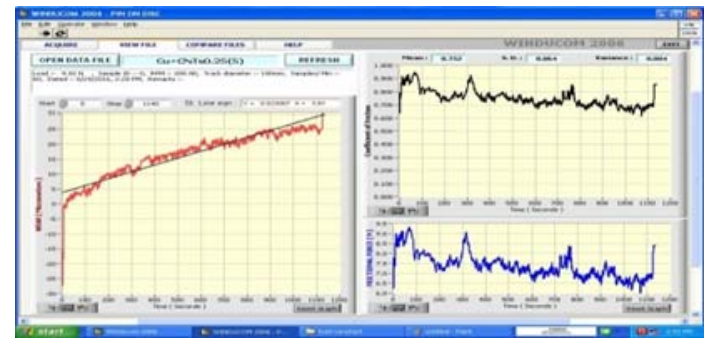

Fig 7(5)

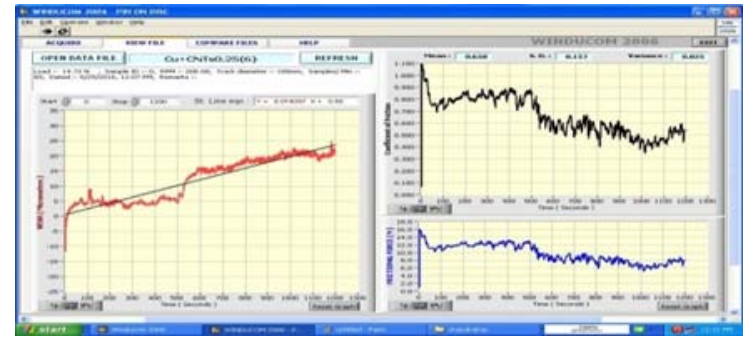

Fig 7(6)

Fig 7(5) $\mathrm{Cu}+\mathrm{MWCNTs} 0.25 \%$ for load $1 \mathrm{~kg}$ and with speed 200rpm Fig 7(6) $\mathrm{Cu}+\mathrm{MWCNTs} 0.25 \%$ for load $1.5 \mathrm{~kg}$ and with speed 200rpm

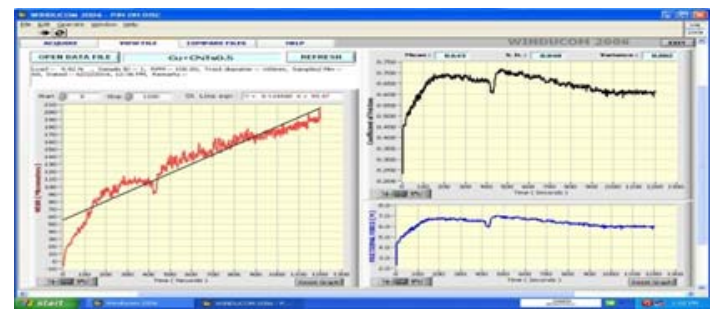

Fig 7(7)

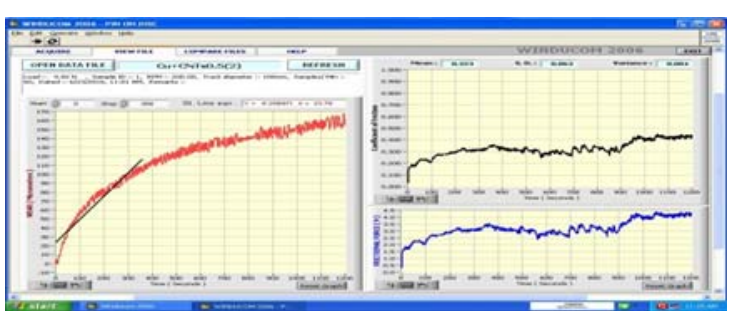

Fig 7(8)

Fig 7(7) $\mathrm{Cu}+\mathrm{MWCNTs} 0.5 \%$ for load $1 \mathrm{~kg}$ and with speed 100rpm Fig 7(8) $\mathrm{Cu}+\mathrm{MWCNTs} 0.5 \%$ for load $1 \mathrm{~kg}$ and with speed 200rpm

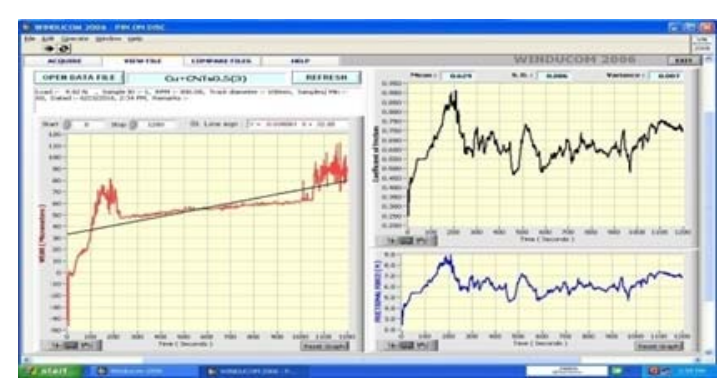

Fig 7(9)

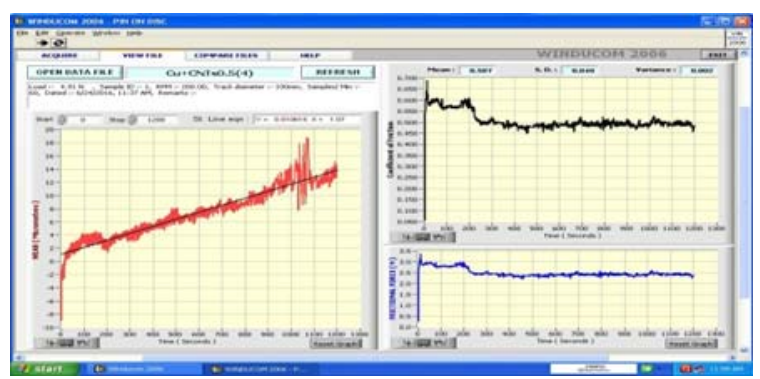

Fig 7(10)

Fig 7(9) Cu+MWCNTs0.5\% for load $1 \mathrm{~kg}$ and with speed 300rpm Fig 7(10) Cu+MWCNTs $0.5 \%$ for load $0.5 \mathrm{~kg}$ and with speed 200rpm 


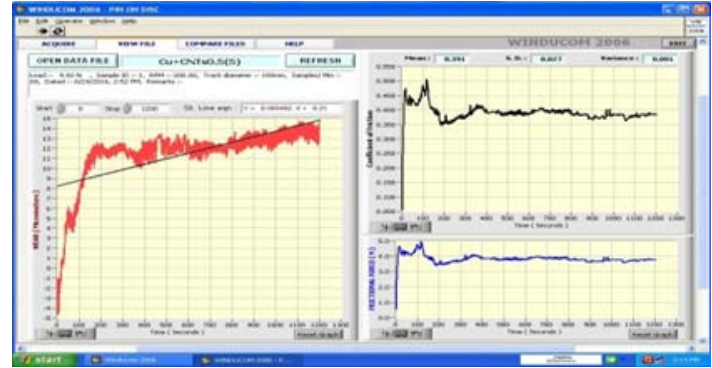

Fig $7(11)$

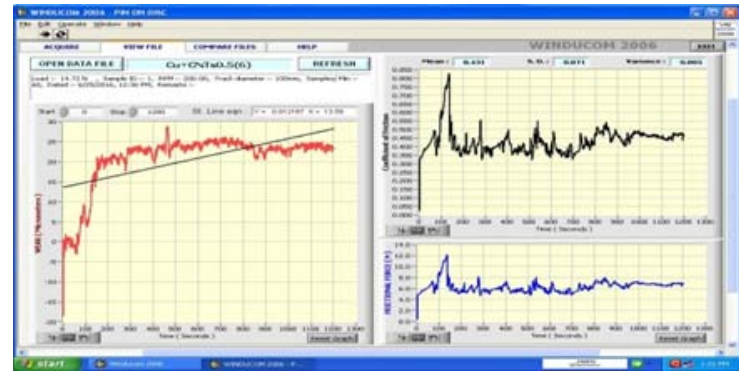

Fig 7(12)

Fig 7(11) Cu+MWCNTs $0.5 \%$ for load $1 \mathrm{~kg}$ and with speed 200rpm Fig 7(12) Cu+MWCNTs $0.5 \%$ for load $1.5 \mathrm{~kg}$ and with speed 200rpm

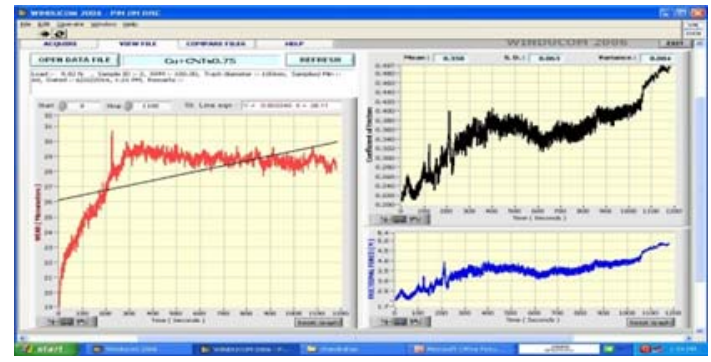

Fig 7(13)

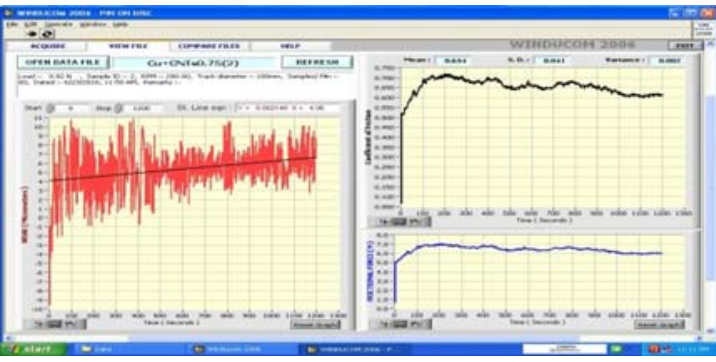

Fig 7(14)

Fig 7(13) Cu+MWCNTs0.75\% for load $1 \mathrm{~kg}$ and with speed 100rpm Fig 7(14) Cu+MWCNTs0.75\% for load $1 \mathrm{~kg}$ and with speed 200rpm

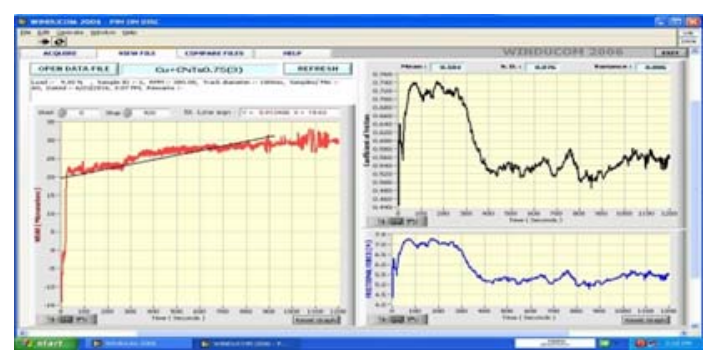

Fig 7(15)

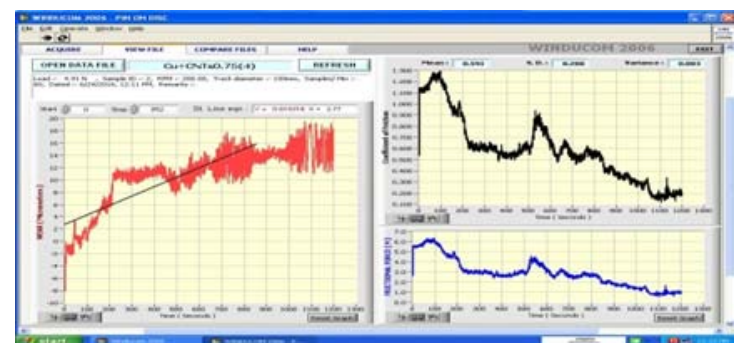

Fig $7(16)$

Fig 7(15) $\mathrm{Cu}+\mathrm{MWCNTs} 0.75 \%$ for load $1 \mathrm{~kg}$ and with speed 300rpm Fig 7(16) $\mathrm{Cu}+\mathrm{MWCNTs} 0.75 \%$ for load $0.5 \mathrm{~kg}$ and with speed 200rpm

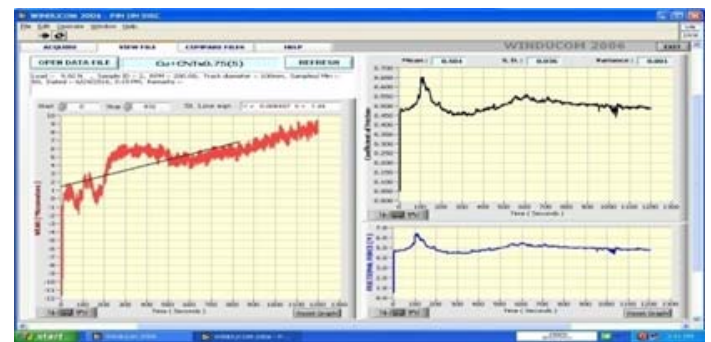

Fig 7(17)

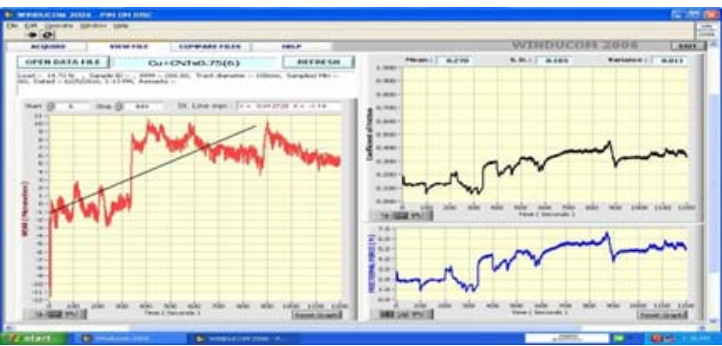

Fig 7(18)

Fig 7(17) $\mathrm{Cu}+\mathrm{MWCNTs} 0.75 \%$ for load $1 \mathrm{~kg}$ and with speed 200rpm Fig 7(18) $\mathrm{Cu}+\mathrm{MWCNTs} 0.75 \%$ for load $1.5 \mathrm{~kg}$ and with speed 200rpm

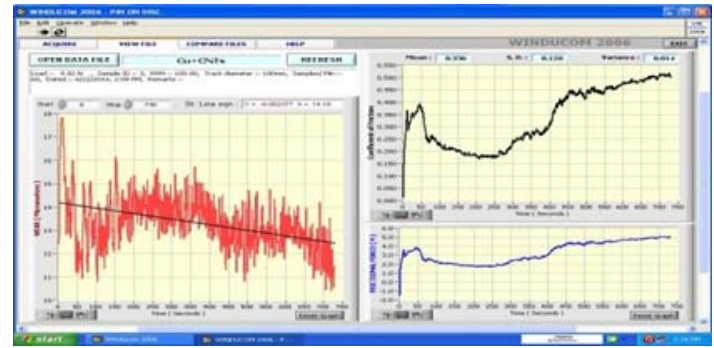

Fig 7(19)

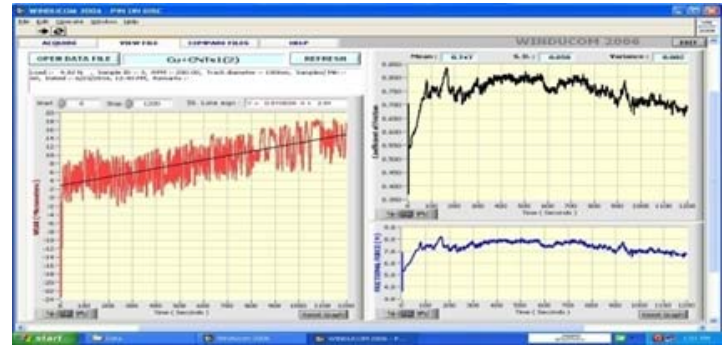

Fig $7(20)$

Fig 7(19) Cu+MWCNTs $1 \%$ for load $1 \mathrm{~kg}$ and with speed 100rpm Fig 7(20) $\mathrm{Cu}+\mathrm{MWCNTs} 1 \%$ for load $1 \mathrm{~kg}$ and with speed 200rpm 


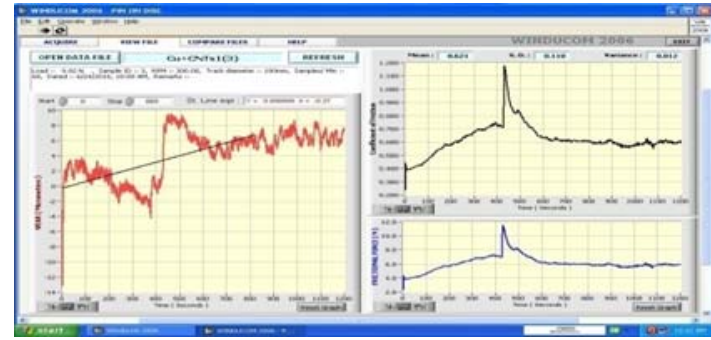

Fig 7(21)

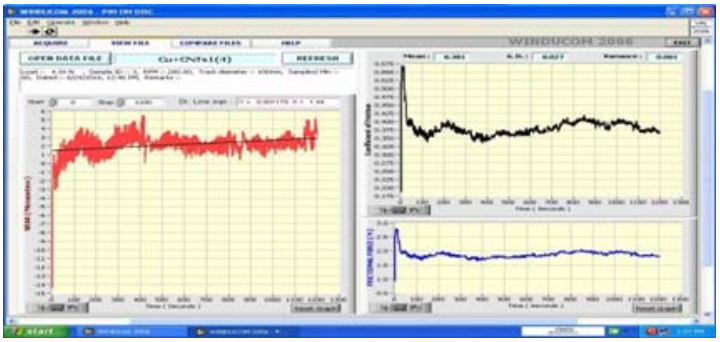

Fig 7(22)

Fig 7(21) $\mathrm{Cu}+\mathrm{MWCNTs} 1 \%$ for load $1 \mathrm{~kg}$ and with speed 300rpm Fig 7(22) $\mathrm{Cu}+\mathrm{MWCNTs} 1 \%$ for load $0.5 \mathrm{~kg}$ and with speed $200 \mathrm{rpm}$

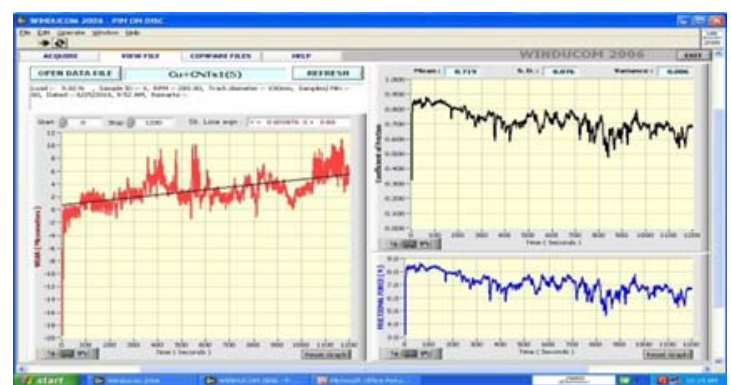

Fig $7(23)$

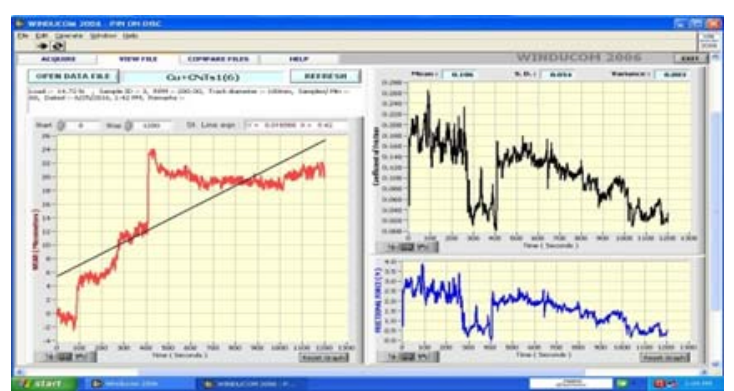

Fig $7(24)$

Fig 7(23) $\mathrm{Cu}+\mathrm{MWCNTs} 1 \%$ for load $1 \mathrm{~kg}$ and with speed 200rpm Fig 7(24) $\mathrm{Cu}+\mathrm{MWCNTs} 1 \%$ for load $1.5 \mathrm{~kg}$ and with speed $300 \mathrm{rpm}$

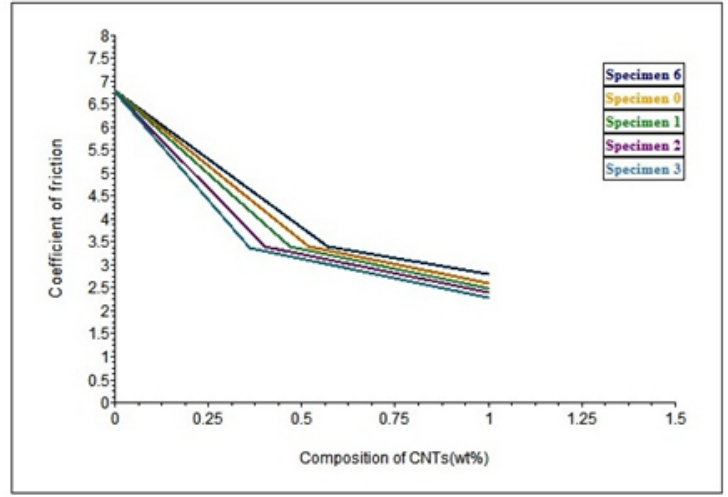

Fig 7.1Coefficient of friction v/s CNTs\% composition of Constant load with varying speed

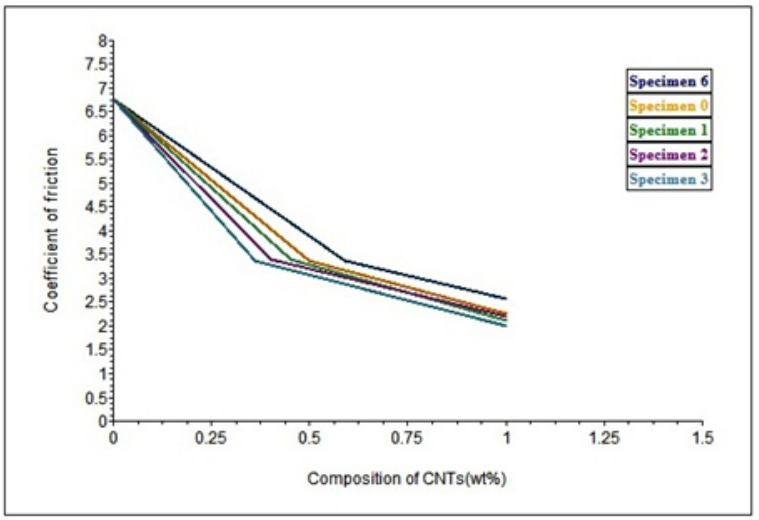

Fig 7.2Coefficient of friction v/s CNTs\% composition of Constant speed with varying load 


\section{IV.CONCLUSION}

$>$ As the densities of both copper powder and carbon nanotubes are different therefore powder metallurgy process is carried out to prepare different weight ratio of nanocomposites and thereafter wire EDM process to is followed to obtain the required testing specimens.

$>$ Microstructure shows even distribution of carbon nanotubes in copper matrix and cavities, deep holes, scratches etc.

$>$ Initiating with hardness test, it is observed that there is increase in hardness value of nanocomposites as the percentage of the carbon nanotubes increased as reinforcement. From the obtained results increase of 3 percent of hardness value for addition of 1.5 percentage carbon nanotubes compared to pure copper specimen.

$>$ Secondly wear properties were determined by conducting wear test, from wear test conducted the coefficient of friction and wear rate are determined and graphs are obtained. Hence from test conducted and graph plotted it is indicated that as the percentage of carbon nanotubes increased as reinforcement in composites there is decrease in both coefficient of friction and wear rate.

$>$ Then it is concluded that non-homogeneous distribution of carbon nanotubes in copper matrix is also likely an enhancement in mechanical and wear properties and hence decreases in friction and wear rate comparing to pure copper composite specimen.

\section{REFERENCES}

[1] Adnan Maqbool, M. Asif Hussain, F. Ahmad Khalid, Nabi Bakhsh, Ali Hussain, Myong HoKim "Mechanical characterization of copper coated carbon nanotubes reinforced aluminum matrix Composites".

[2] Kim Eiroma, Ari Auvinen, Johanna Forsman, Eva-Lena Hult, Jorma Jokiniemi, Pirjo Koskela, Juha Sarlin, Thea SipiläinenMalm,Unto Tapper; VTT Technical Research Centre of Finland; Espoo, Finland. "Development of Conductive Carbon Coated Copper Nanoparticle Inkjet Fluid"

[3] Walid M. Daoushb, Byung K. Lima, Chan B. Moa, Dong H. Nama, Soon H. Honga "Electrical and mechanical properties of carbon nanotube reinforced copper nanocomposites fabricated by electroless deposition process"

[4] Rajendrakumar G Patill, Vishnukanth Chatpalli2 and Ramesh C S3,Dept. of Mechanical Engg, Atria Institute of Technology,KVT \& SDC, Govt. of Karnataka,Dept. of Mechanical Engineering, PES Institute of Technology India

[5] S. Prabhu1*, Shubrajit Bhaumik1 and B. K. Vinayagam2 1School of Mechanical Engineering, SRM University, Chennai-603203, India. 2Mechatronics Engineering Department, SRM University, "Finite element modeling and analysis of zigzag and armchair type single wall carbon nanotube"

[6] International Journal of Engineering \& Technology IJET-IJENS Vol:10 No:04 "Finite Element Modeling of Multi-Walled Carbon Nanotubes"

[7] Journal of Minerals \& Materials Characterization \& Engineering, Vol. 4, No.1, pp 31-46, 2005 jmmce.org "Carbon Nanotube Based Composites- A Review".

[8] Mahani Yusoff and Zuhailawati Hussain, International Journal of Materials, Mechanics and Manufacturing, Vol. 1, No. 3, August 2013 Effect of Sintering Parameters on Microstructure and Properties of Mechanically Alloyed Copper-Tungsten Carbide Composite.

[9] Rajkumar.K and Aravindan.S, "Tribological performance of microwave sintered copper-CNT composites".

[10] Sandeep Mani Tripathi and Tiwari Sushil Bholanath, "Synthesis and Study of Applications of Metal coated Carbon Nanotubes".

[11] http:// www. carbonallotropes . com / carbon - nanotubes / 39 - single - wall - carbon -nanotubes.html.

[12] Manoj Singla., (2009) Study of Wear Properties of Al-SiC Composites. Vol. 8, No.10, pp.813-819, 20090.

[13] Investigation on the Mechanical and Tribological Properties, T. Rameshkumar, I. Rajendran, A. D. Latha, 2010

[14] Standard Test Method for Wear Testing with a Pin-on-Disk, 2000. 